\title{
Researching as Understanding
}

\author{
Roseanna Bourke ${ }^{1} \cdot$ Judith Loveridge ${ }^{2}$
}

Received: 23 June 2016/ Accepted: 23 June 2016/Published online: 7 July 2016

(C) New Zealand Association for Research in Education 2016

This issue brings together diverse ideas proposed by researchers working in education across 10 institutions. The articles in this collection express diversity in the methodological approaches, epistemological underpinnings, cultural foci, and educational contexts and settings. The narratives around data tell a 'story' influenced by the authors' own positions. Perhaps, then, at first glance the authors in this collection as in any other collection have little in common other than presenting a different view on their educational research. However, there are subtle underlying threads that we want to 'pick up' and explore briefly. The idea that something new or novel being initiated (e.g. the first New Zealand school opened 200 years ago as presented by Jones and Jenkins, or an evaluation of a new schoolwide behaviour initiative as outlined by Elder and Prochnow) must be understood in a wider context of the social, economic and cultural imperatives at that time, and from a range of perspectives. This need to understand the phenomenon must come before the initiative or policy premise can be challenged, in order for it either to be sustained, or be prepared to shift with the socio-cultural and economic tides. Some of the articles in this issue highlight cases where new educational initiatives are not sustained, yet a great deal of learning and understanding is gained.

Another thread to consider, and one that is related to the 2016 New Zealand Association for Research in Education (NZARE) annual conference theme, is the 'politics of learning'. Specifically, we note how the unintended consequences of policy impacts directly on both teacher and student learning. There have been both anticipated and unanticipated unintended consequences of education policy in our

Roseanna Bourke

roseanna.bourke@vuw.ac.nz

1 Wellington, New Zealand

2 Victoria University, Wellington, New Zealand 
recent history. For example, the narrowing and reinforcement of a two-tier curriculum as a consequence of national standards was anticipated as an unintended consequence of National Standards and there are indications that this is occurring (Thrupp 2014). Another example has been seen through the introduction and implementation of the Special Education 2000 (SE 2000) framework. While it initially set out to have world-class inclusive education system by the year 2000, it instead had the unintended consequence of aligning the 'special education' funding to students with high needs resulting in the increase of special schools, and the introduction of 'magnet schools'. Therefore, while policy intentions might have a strong educational rationale, factors that contribute to the outcomes of educational policy are complex and multifaceted and include economic, cultural, socio and local politics. Hence it should not be surprising then that there are unintended consequences of policies. Critically, this is one of the reasons why it is important to research how policy 'travels' into communities, schools, classrooms and centres.

The articles by Megan Lourie and Richard Hill are evidence of the value of this type of research. Megan Lourie examines intended and unintended outcomes of Māori language education policy, and argues the way that language education policy is articulated and enacted in practices, frames Māori language revitalisation as a Māori issue or concern. Hence, since the 1980s Māori language education policy has evolved to differentiate outcomes for Māori and non-Māori learners. In her analysis of this situation, she shows the complexity of the factors that contribute to the provision of Māori language education opportunities to all learners. Due to limited funding and limited capacity in terms of teachers, resources have been targeted to Māori-medium schools, on the assumption that they are the most effective language setting for achieving bilingual outcomes. Lourie notes that the 'majority of both Māori and non-Māori learners of Māori language are found within English-medium education settings' but there is no special funding to support Māori language within these settings.

Richard Hill's research using kaupapa Māori research principles provides us with insights to the way these policy decisions play out in the lives of students. He focusses on the issue of school students transitioning from Māori-medium in their primary years to English-medium schooling for their secondary schooling. His study followed five Māori-medium primary school graduates for 3 years after they had transitioned to English-medium secondary schools. While students did well academically there were some challenges in the area of academic English and transitioning to English-medium secondary school impacted negatively on their Māori language. As part of his findings, he highlights 'the importance of teaching academic English to bilingual learners' and proposes 'the question that needs to be answered is whether Māori-medium secondary schools can provide the 'full package' to students, thereby facilitating families' to achieve their goals for their children to remain in Māori-medium education throughout their secondary schooling'.

Alison Jones and Kuni Kaa Jenkins present an account of the first New Zealand school that opened 200 years ago in 1816. While it only stayed viable for 2 years the learning from this account is immense, in terms of how reading and writing were portrayed and understood, and more importantly the different understandings of the 
agenda on 'education' and 'schooling' where questions arise around who should learn, and why. Their storied account brings alive the "energy and hope with which the tupuna (ancestors) first embraced reading and writing-in Maori and in English-as a Maori skill'. Following on from this article, Graham McPhail and Elizabeth Rata 'construct a theoretical curriculum to compare two distinctive curriculum design models: powerful knowledge and 21st learning'. In their article they explore the theory of knowledge, the knowledge structure, the method of conceptual progression and the pedagogical approach of each design model, and conclude that the $21 \mathrm{st}$ learning design has less coherence between the features. The argument within the paper is based on their own 'theoretical model' to distinguish between these two types of curriculum design. It challenges the reader to think about how knowledge is construed and explore his or her own understanding of the philosophy of knowledge.

The article by Linda Bonne moves the reader into the classroom context where she explores the findings from five recent New Zealand-based studies and then sets out to identify patterns in 5-13 year old students' mathematics-related beliefs and attitudes. She concludes that interventions where students are actively supported to develop their mathematics self-efficacy are also more likely to gain progress in their achievement in mathematics. Focusing on students' beliefs and attitudes, alongside their understanding of mathematics, has implications for pedagogical strategies used by teachers, and Bonne suggests an area for future exploration is to understand how teachers use learning conversations. The following article by Barrie Gordon, Ben Dyson, Jackie Cowan, Allison McKenzie and Boaz Shulruf presents their research involving over 487 primary school teachers and their perceptions of the teaching of physical education in their schools. They argue that physical education in New Zealand schools is 'often inconsistent and variable' and that while in their view, quality teaching and learning occurs (using cooperative learning and student involvement in peer and self-assessment as examples of this), a disparity around the resources and planning that went into physical education in contrast to numeracy and literacy was identified.

Katie Elder and Jane Prochnow explore the impact of the newly introduced Ministry of Education initiative into schools, the Positive Behaviour for Learning School-wide (PB4L) with a particular focus on sustainability. This is an intervention framework to support teachers, students and school management to encourage positive behaviour interactions within the school community. In their article, they present the responses of 338 educators who completed the survey from primary and secondary schools. Their mixed-methods study point towards school leadership and capacity building as key to sustaining the new initiative, and they specifically note the importance of the role of the principal.

Barbara Grant examines how Pākehā doctoral supervisors talked about themselves as supervisors of Māori doctoral students. She outlines six different 'leitmotifs' of self, each offering an ethical basis for attentive, relation-centred practice. She proposes the leitmotifs do not belong to an individual but are historically contingent, offering a shared resource of possibilities of sense of self, others, relations and the world. In particular the supervisors were willing to dwell with ghosts of New Zealand's colonial history, be open to the challenges that this brought, and thus show the possibilities in their practices for a better future. 
Collectively these papers highlight the ongoing importance of educational research in contexts where socio-economic and cultural factors impact on how policy and practice within educational settings play out, while also exploring our role as researchers in this, and what we choose to foreground.

Roseanna Bourke and Judith Loveridge

June 2016

\section{Reference}

Thrupp, M. (2014). At the eye of the storm: Researching schools and their communities enacting National Standards. New Zealand Journal of Educational Studies, 49(1), 6-20. 